\title{
Association analysis of podocyte slit diaphragm genes as candidates for diabetic nephropathy
}

\author{
P. Ihalmo • M. Wessman • M. A. Kaunisto • \\ R. Kilpikari • M. Parkkonen • C. Forsblom • \\ H. Holthöfer • P.-H. Groop • \\ for the FinnDiane Study Group
}

Received: 27 June 2007 / Accepted: 18 September 2007 / Published online: 30 October 2007

(C) Springer-Verlag 2007

\begin{abstract}
Aims/hypothesis The slit diaphragm is an adhesion and signalling protein complex linking the interdigitating podocyte foot processes in the kidney glomerulus, and mutations in slit diaphragm-associated genes result in severe proteinuria. Here we report a genetic association analysis of four slit diaphragm genes, LRRC7, KIRREL, NPHS2 and ACTN4, in a Finnish diabetic nephropathy cohort.

Materials and methods A total of 40 single nucleotide polymorphisms (SNPs) were genotyped in 1103 patients with type 1 diabetes. The patients were classified according
\end{abstract}

Electronic supplementary material The online version of this article (doi:10.1007/s00125-007-0854-2) contains supplementary material, which is available to authorised users.

P. Ihalmo $\cdot$ M. Wessman $\cdot$ M. A. Kaunisto $\cdot$ R. Kilpikari •

M. Parkkonen $\cdot$ C. Forsblom $\cdot$ P.-H. Groop $(\square)$

Folkhälsan Institute of Genetics, Folkhälsan Research Center,

University of Helsinki,

Helsinki, Finland

e-mail: per-henrik.groop@helsinki.fi

P. Ihalmo $\cdot$ H. Holthöfer

Department of Bacteriology and Immunology, Haartman Institute, University of Helsinki,

Helsinki, Finland

M. Wessman $\cdot$ M. A. Kaunisto

Finnish Genome Center, University of Helsinki,

Helsinki, Finland

P. Ihalmo $\cdot$ M. Wessman $\cdot$ M. A. Kaunisto $\cdot$ R. Kilpikari •

M. Parkkonen $\cdot$ C. Forsblom $\cdot$ P.-H. Groop

Division of Nephrology, Department of Medicine,

Helsinki University Central Hospital,

Helsinki, Finland

H. Holthöfer

Center for Bioanalytical Sciences, Dublin City University,

Dublin, Ireland to their renal status, and the genotype data were analysed in a cross-sectional case-control setting. To confirm positive associations, four SNPs were genotyped in 1,025 additional patients with type 1 diabetes.

Results No associations with diabetic nephropathy were observed for any of the analysed SNPs. The SNPs were not associated with the time from the onset of diabetes to the diagnosis of nephropathy or with glomerular filtration rate or AER as quantitative variables. In a sex-specific sub-analysis, the variants rs979972 and rs749701 in the first intron of ACTN4 were nominally associated with diabetic nephropathy in females, with odds ratios of 1.81 (95\% CI 1.18 2.79, $p=0.007)$ and 1.93 (95\% CI 1.26-2.96, $p=0.003$ ) respectively.

Conclusions/interpretation Our study has not found any evidence that common variants in LRRC7, KIRREL, NPHS2 and ACTN4 contribute to susceptibility to diabetic nephropathy in Finnish patients with type 1 diabetes.

Keywords Diabetic nephropathy · Proteinuria · Podocytes · Molecular genetics · Glomerular filtration barrier

\author{
Abbreviations \\ ESRD end-stage renal disease \\ MAF minor allele frequency \\ SNP single nucleotide polymorphism
}

\section{Introduction}

Diabetic nephropathy is the leading cause of end-stage renal disease (ESRD) requiring dialysis or renal transplantation, but the predisposing factors and pathogenetic mechanisms of diabetic nephropathy have remained elusive. Family studies have supported a genetic compo- 
nent in the development of the complication [1]. The podocyte foot processes and their interposed slit diaphragms form the outermost layer of the glomerular capillary wall and are responsible for the ultrafiltration of primary urine. Mutations in genes encoding the slit diaphragm lead to rare monogenic forms of proteinuria with variable age of onset and disease severity [2]. Defects in the podocin gene (NPHS2) manifest soon after birth and are characterised by uncontrolled, steroid-resistant proteinuria [3]. Mice lacking the gene encoding the nephrinlike protein NEPH1 (Kirrel) develop massive proteinuria and foot process effacement [4]. Mutations in the ACTN4 gene, which encodes alpha actinin 4 , account for the familial form of focal segmental glomerulosclerosis with later onset of the disease [5]. Densin-180 (LRRC7) was originally identified from synaptic structures in the brain and has recently been reported as a slit diaphragmassociated protein [6]. The slit diaphragm genes can be considered excellent candidate genes for a more common form of proteinuria, diabetic nephropathy. Here, we present a genetic association analysis of LRRC7, KIRREL, NPHS 2 and ACTN4 in Finnish patients with type 1 diabetes.

\section{Materials and methods}

Participants Two sets of Finnish patients with type 1 diabetes were selected for the cross-sectional study
(Table 1). Type 1 diabetes was defined as an age of onset $<35$ years, permanent insulin treatment initiated within 1 year of diagnosis, and a fasting C-peptide level below $0.3 \mathrm{nmol} / \mathrm{l}$. Demographic data and blood and urine samples were collected for the determination of $\mathrm{HbA}_{1 \mathrm{c}}$, AER and serum creatinine level. The study protocol was approved by the ethics committees of the participating centres and followed the principles of the Declaration of Helsinki. Informed consent was obtained from all patients.

The nephropathy status of the patients was ascertained, and four classes were generated (Table 1). Normoalbuminuria was defined as an AER less than $30 \mathrm{mg} / 24 \mathrm{~h}$ or $20 \mu \mathrm{g} / \mathrm{min}$ in an overnight urine collection, and the patients were required to have a duration of diabetes longer than 15 years to ensure their renal status. Patients with microalbuminuria had an AER between 30 and $300 \mathrm{mg} / 24 \mathrm{~h}$ or between 20 and $200 \mu \mathrm{g} / \mathrm{min}$, and patients with macroalbuminuria an AER $>300 \mathrm{mg} / 24 \mathrm{~h}$ or $>200 \mu \mathrm{g} / \mathrm{min}$. ESRD patients were either on dialysis or had received a kidney transplant. It was required that AER in at least two out of three consecutive $24 \mathrm{~h}$ or overnight urine collections exceeded the threshold for classification. The $24 \mathrm{~h}$ AER and serum creatinine values in Table 1 represent the single last central laboratory measurements, and some patients showed values deviating from the values used for the classification at the time of the investigation. Altogether, 32 patients in the normoalbuminuria class $(n=1,066)$ presented with an AER exceeding $30 \mathrm{mg} / 24 \mathrm{~h}$. The GFR was

Table 1 Clinical characteristics of the patients

\begin{tabular}{|c|c|c|c|c|c|c|}
\hline & \multicolumn{3}{|l|}{ Study sample I } & \multicolumn{3}{|l|}{ Study sample II } \\
\hline & $\begin{array}{l}\text { Normoalbuminuria } \\
(n=459)\end{array}$ & $\begin{array}{l}\text { Microalbuminuria } \\
(n=276)\end{array}$ & $\begin{array}{l}\text { Macroalbuminuria } \\
(n=368)\end{array}$ & $\begin{array}{l}\text { Normoalbuminuria } \\
(n=607)\end{array}$ & $\begin{array}{l}\text { Macroalbuminuria } \\
(n=158)\end{array}$ & $\begin{array}{l}\text { ESRD } \\
(n=260)\end{array}$ \\
\hline Male/female (\%) & $40 / 60$ & $59 / 41$ & $60 / 40$ & $47 / 53$ & $54 / 46$ & $60 / 40$ \\
\hline Age (years) & $42.9 \pm 10.0$ & $37.1 \pm 10.9$ & $39.3 \pm 9.0$ & $39.5 \pm 12.1$ & $44.5 \pm 10.5$ & $44.0 \pm 8.0$ \\
\hline $\begin{array}{l}\text { Diabetes duration } \\
\text { (years) }\end{array}$ & $29.0 \pm 6.8$ & $25.0 \pm 9.4$ & $27.2 \pm 6.4$ & $25.3 \pm 10.4$ & $34.2 \pm 9.4$ & $32.6 \pm 7.7$ \\
\hline $\begin{array}{l}\text { Diabetes duration } \\
\text { to diabetic } \\
\text { nephropathy } \\
\text { (years) }\end{array}$ & - & - & $18.4 \pm 6.3$ & - & $23.5 \pm 9.7$ & $19.8 \pm 7.4$ \\
\hline BMI $\left(\mathrm{kg} / \mathrm{m}^{2}\right)$ & $24.9 \pm 2.9$ & $25.6 \pm 3.6$ & $25.8 \pm 3.9$ & $25.0 \pm 3.4$ & $25.6 \pm 3.8$ & $24.1 \pm 3.6$ \\
\hline $\begin{array}{l}\text { Systolic blood } \\
\text { pressure }(\mathrm{mmHg})\end{array}$ & $132 \pm 16$ & $136 \pm 17$ & $144 \pm 19$ & $131 \pm 17$ & $146 \pm 22$ & $153 \pm 23$ \\
\hline $\begin{array}{l}\text { Diastolic blood } \\
\text { pressure }(\mathrm{mmHg})\end{array}$ & $78 \pm 9$ & $81 \pm 10$ & $84 \pm 10$ & $78 \pm 10$ & $81 \pm 11$ & $86 \pm 12$ \\
\hline $\mathrm{HbA}_{1 \mathrm{c}}(\%)$ & $8.1 \pm 1.1$ & $8.8 \pm 1.4$ & $9.0 \pm 1.6$ & $8.3 \pm 1.3$ & $9.1 \pm 1.5$ & $8.6 \pm 1.5$ \\
\hline AER (mg/24 h) & $7(1-85)$ & $59(2-613)$ & $588(4-8348)$ & $8(1-101)$ & $426(11-4609)$ & - \\
\hline $\begin{array}{l}\text { GFR }\left(\mathrm{ml} \mathrm{min}^{-1}\right. \\
\left.1.73 \mathrm{~m}^{-2}\right)\end{array}$ & $89.5 \pm 18.2$ & $95.5 \pm 25.5$ & $64.8 \pm 32.0$ & $96.4 \pm 24.4$ & $61.3 \pm 29.4$ & - \\
\hline $\begin{array}{l}\text { Serum creatinine } \\
(\mathrm{mmol} / \mathrm{l})\end{array}$ & $84(43-144)$ & $89(35-194)$ & $127(20-1278)$ & $83(20-238)$ & $126(46-728)$ & - \\
\hline
\end{tabular}

Data are mean \pm SD or median (range) 
estimated using the Cockcroft-Gault formula adjusted for body surface area [7].

Power calculations A relative risk of 1.6 and a recessive model of inheritance were assumed, and the prevalence of diabetic nephropathy in type 1 diabetes was set to $20 \%$. The powers attained with minor allele frequencies (MAFs) 0.05 , 0.25 and 0.40 were $0.06,0.64$ and $0.98 \quad(p=0.05)$ respectively using the sample size of 1066 individuals with normoalbuminuria and 786 with diabetic nephropathy. Power calculations were performed with the Genetic Power Calculator (http://pngu.mgh.harvard.edu/ purcell/gpc/).

Markers and genotyping Forty SNPs were genotyped successfully [Table 2; Electronic supplementary material (ESM) Table 1, ESM Fig. 1); we attempted to genotype five other SNPs but either the attempt failed or the SNPs were out of Hardy-Weinberg equilibrium. The SNPs were required to have a MAF $>0.05$ in the Centre d'Etude du Polymorphisme Humain $(\mathrm{CEPH})$ population. The SNPs captured $73 \%$ of SNPs for NPHS2 and $83 \%$ for ACTN4 according to the HapMap data (pairwise tagging with $r^{2}>0.8$ using the Tagger program; HapMap Public Release 20, January 2006). For KIRREL, we chose evenly distributed SNPs with an interval of 6-14 kb, and for $L R R C 7$ we chose those with an interval of 5-216 kb. The SNPs were determined from DNA extracted from peripheral blood, and genotyping was performed using the Homogeneous Mass-extend MassArray System (Sequenom, San Diego, CA, USA) or the ABI Prism 7900 Sequence Detection System (Applied Biosystems, Foster City, CA, USA). Genotyping quality was ensured by using $2 \%$ internal controls in each run, for which complete accuracy was demanded. The average genotyping success rate was over $99 \%$.

Single-marker and haplotype analysis Allele and genotype frequencies of SNPs were compared with the $\chi^{2}$ test. A logistic regression model with diabetic nephropathy as the dependent variable was used to estimate the independent association of SNPs. Sex, duration of diabetes, $\mathrm{HbA}_{1 \mathrm{c}}$ and systolic and diastolic blood pressures were included as covariates. Quantitative traits were evaluated by ANOVA or the non-parametric Kruskal-Wallis test. Haploview version 3.2 was used to determine linkage disequilibrium values and to estimate haplotypes. A $p$ value below 0.05 was considered statistically significant.

\section{Results}

Genotype distributions were in Hardy-Weinberg equilibrium. The genotype and allele frequencies of the SNPs were compared between the patients with normoalbuminuria and those with macroalbuminuria in study sample 1 . We observed no association for any of the analysed SNPs with macroalbuminuria (Table 2; ESM Table 1). The SNPs were not associated with microalbuminuria either (data not shown). We further compared the estimated haplotype frequencies within the haplotype blocks (confidence intervals), but none of them yielded statistically significant results (data not shown).

The genetic association of the SNPs with kidney function was also assessed using quantitative variables. However, no differences regarding AER, GFR or serum creatinine levels or time from the onset of type 1 diabetes to development of diabetic nephropathy were observed (data not shown).

Stratification by sex yielded nominal evidence of association with macroalbuminuria for four SNPs in ACTN4 in female participants, and these SNPs were selected for genotyping in the second study sample. In the joint analysis of both study samples, the associations for the SNPs rs979972 (odds ratio $1.81,95 \%$ CI $1.18-2.79, p=0.007$ ) and rs 749701 (odds ratio $1.93,95 \%$ CI $1.25-2.96, p=0.003$ ) remained significant in female patients with diabetes (for additional analyses see ESM Table 2). Similarly, significant associations were not observed in the male patients with diabetes. Notably, the patients with macroalbuminuria and those with ESRD were pooled in this analysis.

\section{Discussion}

This study reports a genetic association analysis of four slit diaphragm-associated genes, LRRC7, KIRREL, NPHS2 and $A C T N 4$, in a Finnish patient cohort with type 1 diabetes and diabetic nephropathy. The analysed genes did not associate with diabetic nephropathy or with any other clinical variable reflecting the kidney filtration function.

No genetic involvement of KIRREL or LRRC7 in human disease has been reported previously to our knowledge, and this study provides no proof of such an involvement either. Furthermore, our results are in agreement with a previous report excluding linkage to diabetic ESRD for the NPHS2 and ACTN4 loci in White and African-American populations [8]. The only functional polymorphism studied here, R229Q in the NPHS2 gene, has been suggested to contribute to susceptibility to microalbuminuria in the general population [9]. However, we could not establish such a relationship between AER and the R229Q variant, or any other variant in the NPHS2 gene, in patients with type 1 diabetes.

The sex-specific sub-analysis suggested that common variants (rs979972 and rs749701) in the first intron of ACTN4 may predispose to diabetic nephropathy in female participants. Alpha actinin 4 is not a slit diaphragm protein per se, but is located in the vicinity of the slit diaphragm in 
Table 2 Genotyped SNPs in the LRRC7, KIRREL, NPHS2 and ACTN4 genes and their minor allele frequencies (MAF)

\begin{tabular}{|c|c|c|c|c|}
\hline \multirow[t]{2}{*}{$\mathrm{SNP}^{\mathrm{a}}$} & \multicolumn{2}{|l|}{ MAF $^{\mathrm{b}}(\%)$} & \multirow[t]{2}{*}{ Adjusted odds ratio ${ }^{c}(95 \% \mathrm{CI})$} & \multirow[t]{2}{*}{$p$ value } \\
\hline & Normoalbuminuria & Macroalbuminuria & & \\
\hline \multicolumn{5}{|c|}{ LRRC7 (chromosome 1) } \\
\hline rs765795 & 0.32 & 0.33 & $1.00(0.58-1.73)$ & 0.999 \\
\hline rs 10889850 & 0.31 & 0.30 & $1.06(0.60-1.88)$ & 0.833 \\
\hline rs1361494 & 0.38 & 0.40 & $1.19(0.73-1.92)$ & 0.485 \\
\hline rs2421306 & 0.44 & 0.41 & $0.71(0.44-1.14)$ & 0.157 \\
\hline rs659181 & 0.30 & 0.31 & $1.29(0.73-2.30)$ & 0.386 \\
\hline \multicolumn{5}{|c|}{ KIRREL (chromosome 1) } \\
\hline rs4246539 & 0.16 & 0.17 & $1.20(0.42-3.43)$ & 0.731 \\
\hline rs6656063 & 0.40 & 0.41 & $0.96(0.59-1.55)$ & 0.854 \\
\hline rs 11580742 & 0.16 & 0.14 & $0.80(0.31-2.11)$ & 0.655 \\
\hline rs6666443 & 0.08 & 0.07 & $1.82(0.33-10.09)$ & 0.493 \\
\hline rs6661149 & 0.07 & 0.06 & $1.12(0.15-8.28)$ & 0.915 \\
\hline rs6686246 & 0.13 & 0.10 & $0.54(0.15-1.98)$ & 0.356 \\
\hline rs7527735 & 0.28 & 0.28 & $1.02(0.56-1.85)$ & 0.961 \\
\hline rs1925032 & 0.21 & 0.19 & $0.53(0.20-1.37)$ & 0.188 \\
\hline rs 7368400 & 0.48 & 0.46 & $0.93(0.59-1.46)$ & 0.743 \\
\hline rs12033891 & 0.16 & 0.16 & $0.56(0.18-1.76)$ & 0.317 \\
\hline rs 7367384 & 0.47 & 0.51 & $1.52(0.95-2.42)$ & 0.080 \\
\hline rs874844 & 0.45 & 0.42 & $0.70(0.44-1.13)$ & 0.143 \\
\hline rs17421546 & 0.04 & 0.04 & $0.75(0.41-1.39)$ & 0.364 \\
\hline \multicolumn{5}{|c|}{ NPHS2 (chromosome 1) } \\
\hline rs11585517 & 0.30 & 0.32 & $1.08(0.62-1.89)$ & 0.794 \\
\hline rs1410586 & 0.13 & 0.12 & $0.61(0.07-5.80)$ & 0.668 \\
\hline rs 10913815 & 0.28 & 0.28 & $1.17(0.63-2.15)$ & 0.620 \\
\hline rs1410589 & 0.33 & 0.34 & $1.29(0.75-2.21)$ & 0.351 \\
\hline rs 2274622 & 0.23 & 0.24 & $1.01(0.50-2.09)$ & 0.987 \\
\hline rs 2274625 & 0.19 & 0.16 & $0.32(0.09-1.12)$ & 0.075 \\
\hline rs 2274626 & 0.31 & 0.33 & $0.94(0.55-1.61)$ & 0.811 \\
\hline $\mathrm{R}_{229 Q^{\mathrm{d}}}$ & 0.05 & 0.06 & $1.47(0.88-2.46)$ & 0.138 \\
\hline rs6698089 & 0.05 & 0.05 & $1.09(0.63-1.87)$ & 0.765 \\
\hline rs6657893 & 0.24 & 0.22 & $0.69(0.33-1.46)$ & 0.329 \\
\hline rs3738423 & 0.12 & 0.11 & $1.16(0.80-1.70)$ & 0.441 \\
\hline rs3829795 & 0.36 & 0.32 & $0.82(0.63-1.06)$ & 0.128 \\
\hline \multicolumn{5}{|c|}{ ACTN4 (chromosome 19) } \\
\hline rs979972 & 0.49 & 0.52 & $1.41(0.90-2.21)$ & 0.136 \\
\hline rs888995 & 0.12 & 0.13 & $1.11(0.36-3.39)$ & 0.853 \\
\hline rs6508813 & 0.25 & 0.27 & $1.48(0.81-2.70)$ & 0.206 \\
\hline rs973009 & 0.10 & 0.09 & $2.88(0.41-20.28)$ & 0.288 \\
\hline rs2112650 & 0.17 & 0.17 & $0.71(0.29-1.70)$ & 0.437 \\
\hline rs4802744 & 0.20 & 0.22 & $1.27(0.58-2.80)$ & 0.556 \\
\hline rs749701 & 0.41 & 0.44 & $1.37(0.87-2.16)$ & 0.174 \\
\hline rs749702 & 0.12 & 0.12 & $1.02(0.33-3.17)$ & 0.979 \\
\hline rs2086148 & 0.03 & 0.02 & $0.77(0.37-1.61)$ & 0.492 \\
\hline rs1060186 & 0.27 & 0.24 & $1.48(0.81-2.71)$ & 0.207 \\
\hline
\end{tabular}

The genetic association of the SNPs with macroalbuminuria was assessed with a regression model adjusted for sex, duration of diabetes, $\mathrm{HbA}_{1 \mathrm{c}}$ and blood pressure

${ }^{a}$ Reference identification number (rs) according to the HapMap database (Release 20, January 2006)

${ }^{\mathrm{b}}$ The minor allele as denoted as in ESM Table 1

${ }^{\mathrm{c}}$ Patients homozygous for the minor allele (2/2) were compared with patients homozygous for the major allele $(1 / 1)$

d The non-synonymous R229Q SNP in NPHS2 characterised by Tsukaguchi et al. [13] was included

the cytoskeleton of the podocyte foot process [5]. Interestingly, the alpha actinin 4 mRNA is underexpressed in the glomeruli of patients with microalbuminuria compared with patients with normal AER [10]. In addition, a combination of glucose and advanced glycation end-products reduced the expression of alpha actinin- 4 at both the protein and the 
mRNA level in podocytes in vitro [11]. Whether or not the observed variation in ACTN4 represents a true association remains to be determined in replication studies in other populations.

The analysed patients represented a carefully characterised study sample with a genetically homogeneous background from the Finnish population, which has the highest incidence rate of type 1 diabetes in the world [12], and the genotyping and statistical methods used in this study represent the state of the art. The SNP coverage can be considered sufficient to detect haplotype variation in the NPHS2 and ACTN4 genes. It is, however, of note that the five analysed SNPs in the LRRC7 gene do not necessarily capture all possible causative variants. It is also important to note that, with the present study design, we cannot exclude the existence of rare variants in some cases of diabetic nephropathy.

In conclusion, this study does not provide evidence for a genetic association of LRRC7, KIRREL, NPHS2 or ACTN4 with diabetic nephropathy in Finnish patients with type 1 diabetes.

Acknowledgements We warmly thank all the patients who have participated in the FinnDiane study and acknowledge the physicians and nurses at each centre who have assisted in studying the patients (see ESM). This study was supported by the European Union (LSHB-CT2003-503364), the Wilhelm and Else Stockmann Foundation, the Folkhälsan Research Foundation, the Finnish Kidney Foundation (P. Ihalmo), the Kyllikki and Uolevi Lehikoinen Foundation (P. Ihalmo), the Sigrid Juselius Foundation, the Finnish Diabetes Association, Medicinska Understödsföreningen Liv och Hälsa and the Academy of Finland (214335 to M. Wessman). The skilled technical assistance of Sinikka Lindh and Anna Sandelin is gratefully acknowledged.

Duality of interest The authors declare that there is no duality of interest associated with this manuscript.

\section{References}

1. Harjutsalo V, Katoh S, Sarti C, Tajima N, Tuomilehto J (2004) Population-based assessment of familial clustering of diabetic nephropathy in type 1 diabetes. Diabetes 53:2449-2454

2. Kriz W (2005) TRPC6 - a new podocyte gene involved in focal segmental glomerulosclerosis. Trends Mol Med 11:527-530

3. Boute N, Gribouval O, Roselli S et al (2000) NPHS2, encoding the glomerular protein podocin, is mutated in autosomal recessive steroid-resistant nephrotic syndrome. Nat Genet 24:349-354

4. Donoviel DB, Freed DD, Vogel H et al (2001) Proteinuria and perinatal lethality in mice lacking NEPH1, a novel protein with homology to NEPHRIN. Mol Cell Biol 21:4829-4836

5. Kaplan JM, Kim SH, North KN et al (2000) Mutations in ACTN4, encoding alpha-actinin-4, cause familial focal segmental glomerulosclerosis. Nat Genet 24:251-256

6. Ahola H, Heikkilä E, Åström E et al (2003) A novel protein, densin, expressed by glomerular podocytes. J Am Soc Nephrol 14:1731-1737

7. Cockcroft DW, Gault MH (1976) Prediction of creatinine clearance from serum creatinine. Nephron 16:31-41

8. Iyengar SK, Fox KA, Schachere M et al (2003) Linkage analysis of candidate loci for end-stage renal disease due to diabetic nephropathy. J Am Soc Nephrol 14:S195-S201

9. Pereira AC, Pereira AB, Mota GF et al (2004) NPHS2 R229Q functional variant is associated with microalbuminuria in the general population. Kidney Int 65:1026-1030

10. Nosadini R, Velussi M, Brocco E et al (2005) Altered transcapillary escape of albumin and microalbuminuria reflects two different pathogenetic mechanisms. Diabetes 54:228-233

11. Ha TS (2006) High glucose and advanced glycosylated endproducts affect the expression of alpha-actinin-4 in glomerular epithelial cells. Nephrology (Carlton) 11:435-441

12. Tuomilehto J, Karvonen M, Pitkaniemi J et al (1999) Record-high incidence of type I (insulin-dependent) diabetes mellitus in Finnish children. The Finnish Childhood Type I Diabetes Registry Group. Diabetologia 42:655-660

13. Tsukaguchi H, Sudhakar A, Le TC et al (2002) NPHS2 mutations in late-onset focal segmental glomerulosclerosis: R229Q is a common disease-associated allele. J Clin Invest 110:1659-1666 